\title{
Photochromic properties of composite films of thermally irreversible diarylethenes and fulgimides in polytetrafluoroethylene matrix
}

\author{
O.I. Kobeleva ${ }^{1}$, T.M. Valova ${ }^{1}$, A.O. Ait ${ }^{1}$, V.A. Barachevsky ${ }^{1}$, K.P. Grytsenko ${ }^{2}$, \\ V.F. Machulin', M.M. Krayushkin ${ }^{3}$ \\ ${ }^{1}$ Photochemistry Center, Russian Academy of Sciences, \\ 7a, bld.1, Novatorov str., Moscow, 119421, Russian Federation \\ E-mail: barva@photonics.ru \\ ${ }^{2}$ Lashkaryov Institute of Semiconductor Physics, Ukrainian National Academy of Sciences, \\ 41, prospect Nauky, 03028 Kyiv, Ukraine \\ E-mail:d.grytsenko@gmail.com \\ ${ }^{3}$ N.D. Zelinsky Institute of Organic Chemistry, Russian Academy of Sciences, \\ 47, Leninsky Ave., Moscow, 119991, Russian Federation \\ E-mail: mkray@ioc.ac.ru
}

\begin{abstract}
Photochromic polymeric thin films have been prepared by vacuum codeposition of polytetrafluoroethylene (PTFE) and thermally irreversible photochromic compounds: the cyclopentene derivative of diarylethene and fulgimide. Their photochromic properties were studied using the spectral-kinetic method as compared with polymethyl methacrylate (PMMA) films filled with the same photochromic compounds prepared using the spin coating method. The films prepared using codeposition in vacuum are characterized by photochromic properties acceptable for recording media for 3D optical memory.
\end{abstract}

Keywords: photochromism, diarylethene, fulgimide, co-deposition, spectroscopy, optical memory.

Manuscript received 11.07.11; revised manuscript received 02.09.11; accepted for publication 14.09.11; published online 30.11.11.

\section{Introduction}

Applications of photochromic polymeric systems in information technologies require development of new methods for easy fabrication of photochromic films with reproducibility of their characteristics. One of the methods is co-deposition of organic compounds and polytetrafluoroethylene (PTFE) in vacuum [1] widely used in industry for other compounds. The peculiarity of our method is thermal evaporation of PTFE when vapors are activated by a cloud of electrons. The main advantage of this method is that both the vapor phase and growing film are not subjected to the action of energetic electrons, and, consequently, destruction of organic molecules is impossible. Earlier this method was used for preparation of thin polymeric films with the use of thermally relaxing spiropyrans [2].
This paper is devoted to application of the above mentioned method for preparation of composite films based on PTFE and thermally irreversible photochromic compounds from diarylethene [3] and fulgimide [4] classes and researches of their properties. These photochromic compounds are of interest for development of 3D optical memory [5].

\section{Experimental}

Two photochromic compounds, namely, diarylethene I and fulgimide II, were used for co-deposition together with PTFE as well as for preparation of polymethyl methacrylate (PMMA) films filled with compounds by using the spin-coating method. 


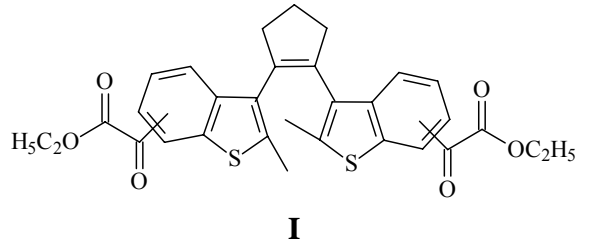<smiles>CC(C)=C1C(=O)N(NC(=O)OC(C)(C)C)C(=O)/C1=C(/C)c1cc(C)sc1C</smiles>

II

The equipment and co-deposition method were before described in details [2]. The deposition installation $\mathrm{YBH}-74$ equipped with the Pfeiffer vacuum pressure meter, Sigma quartz thickness monitor and StellarNet optical spectrometer was used for preparation of composite thin films. Compounds were evaporated at the pressure of $10^{-3} \mathrm{~Pa}$ in a silica crucible. Bulk PTFE pellets were evaporated in the metal crucible with consequent vapour activation with electron cloud emitted by a heated tungsten wire. Due to simultaneous condensation of dye molecules and active fragments of the PTFE molecule, the composite solid films were grown on solid surfaces. Glass and silica slides were used as substrates. The film thickness was 30 to $60 \mathrm{~nm}$.

Photochromic films based on PMMA were prepared using the spin coating method on silica plates by using solution of chloroform and chlorobenzene (1:1) containing PMMA $(5 \mathrm{wt} \%)$ and the photochromic compound ( 25 weight $\%$ from a weight of dry polymer). Then, the films were dried at $60{ }^{\circ} \mathrm{C}$ for $30 \mathrm{~min}$ in a drying chamber. The film thickness was about $1 \mu \mathrm{m}$. Photostationary absorption spectra, photocoloration kinetics, photobleaching and photodegradation were measured using the spectrophotometer "Ocean Optics". Photochromic characteristics were measured for the films with various concentrations of photochromic compounds.

The films were irradiated by filtered light from the Hamamatsu LC -8 bulb. For film photocoloration the light-filter УФС-1 was used. Photobleaching of the film was achieved by irradiation from the same bulb through the light-filter $Ж \mathrm{C}-16$. The photodegradation process was studied under non-filtered light. All experiments were carried out using the light-filter $\mathrm{C} 3 \mathrm{C}-24$ and the metal net transmitting $15 \%$ of falling light for elimination of the thermal effect on photochromic transformations.

\section{Results and discussion}

It is well known [3, 4] that the colourless open form A and the colored cyclic form $\mathrm{B}$ of photochromic diarylethenes and fulgimides manifest reversible photoinduced valence isomerisation only under UV and visible light, respectively.
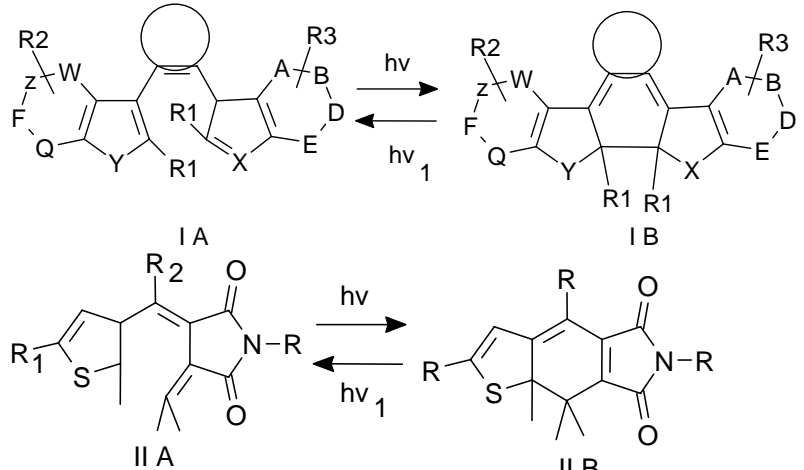

Spectral-kinetic studies of prepared films have been presented in Table and Figures 1 to 3. Fig. 1 shows photoinduced changes of absorption spectra for the compound I in PTFE. Kinetic curves for photocoloration and photobleaching processes have been presented in Fig. 2.

It is seen from Figs. 1 and 2 that the composite film manifests photochromic properties. Both forms are thermally stable in darkness. The optical density at the maximum of the absorption band for the photoinduced in the photoequilibrium state form was not changed for several days. Comparison of the results of the spectralkinetic studies for the films based on the compound I in the PTFE matrix and prepared by the spin-coating with PMMA showed that films are characterized by the different value of photoinduced optical density at the maximum of absorption bands for the form $\mathrm{B}$ at the same value of photoinduced optical density of the initial form (Table). It means that the light sensitivity (the value $\Delta D_{\mathrm{B}}^{\text {phot }}$ at the same optical density for the initial form) of vacuum evaporated films is lower than that of films prepared by the spin-coating method. It may be caused by a small free molecular volume and absence of residual solvent in PTFE matrix.

The value of photoinduced optical density depends on the concentration of the initial form $A$ of the compound I in polymer films prepared by vacuum codeposition (Fig. 3).

The relative study of photodegradation of photochromic properties for prepared photochromic films filled with the diarylethene, has been carried out. Results are presented in Fig. 4.

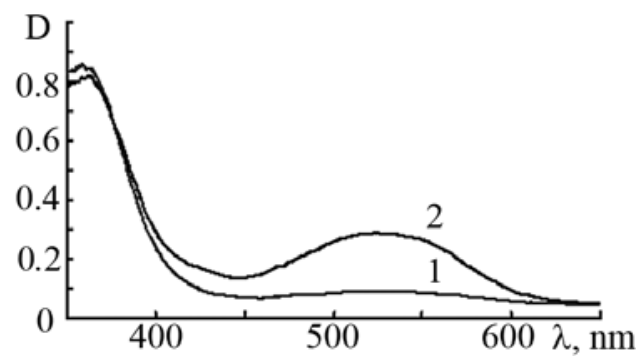

Fig. 1. Absorption spectra of the photochromic film based on the compound I and PTFE before (1) and after(2) UV irradiation. 


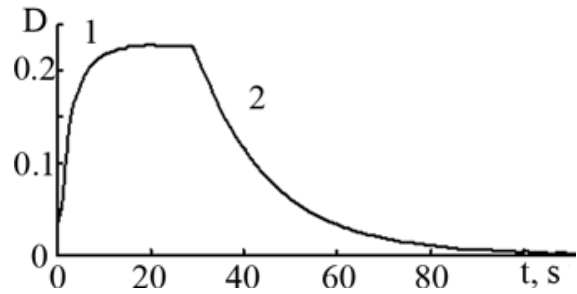

Fig. 2. Kinetic curves for processes of photocoloration under UV irradiation through the filter $У \Phi C-1$ (1) and photobleaching under visible irradiation through the filter ЖC-16 (2) for the film based on the compound I and PTFE at the maximum absorption band of the form $\mathrm{B}$.

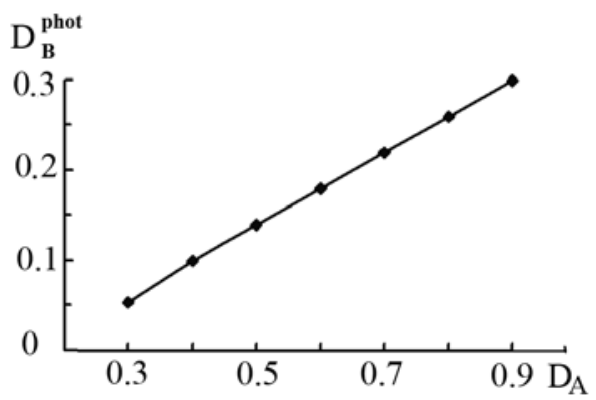

Fig. 3. Dependence between values of optical density of the initial form $\mathrm{A}$ and photoinduced optical density at the maximum of absorption band of the form $\mathrm{B}$.

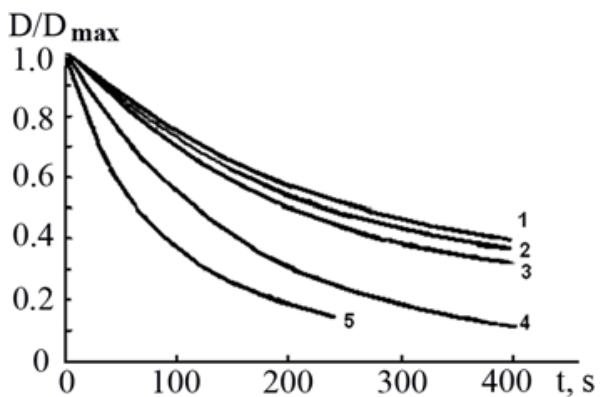

Fig. 4. Normalized kinetic curves of the photodegradation process for the films based on photochromic diarylethene I and PTFE $(1-3)$ or PMMA $(4,5)$ at $D_{\mathrm{A}}=1.1(1), 0.92(2), 0.8(3)$, $0.4(4), 0.35$ (5).

Fig. 4 shows that the stability to irreversible phototransformations grows with increasing the concentration of diarylethene $I$ in the film of the same thickness (Fig. 4, curves 1-3). At the same concentration of diarylethene I, the films based on PTFE were more photostable as compared with the films based on PMMA (Fig. 4, curves 4 and 5). The spectral-kinetic study of phototransformation of the PTFE films filled with fulgimide II (Figs.5, 6, Table) showed that these films exhibit photochromic properties.

As for the same films with the compound I, light sensitivity to UV irradiation for films based on PMMA and the compound II was higher than for the films based on PTFE (Table). The value of photoinduced optical density in the equilibrium state was unchanged for several days.
Table. Spectral-kinetic characteristics of photochromic dye-filled polymer films.

\begin{tabular}{|c|c|c|c|c|c|}
\hline Compound & $\begin{array}{c}\text { Polymer } \\
\text { binder }\end{array}$ & $\begin{array}{l}\lambda_{\mathrm{A}}, \\
\mathrm{nm}\end{array}$ & $D_{\mathrm{A}}$ & $\begin{array}{l}\lambda \mathrm{B}, \\
\mathrm{nm}\end{array}$ & $\Delta D_{\mathrm{B}}^{\text {phot }}$ \\
\hline I & PTFE & \multirow[t]{2}{*}{362} & 1.10 & \multirow[t]{2}{*}{530} & 0.30 \\
\hline I & PTFE & & 0.40 & & 0.08 \\
\hline $\mathrm{I}$ & PMMA & 357 & 0.35 & 523 & 0.15 \\
\hline II & PTFE & \multirow{2}{*}{335} & 0.39 & \multirow{2}{*}{535} & 0.18 \\
\hline II & PTFE & & 0.29 & & 0.12 \\
\hline II & PMMA & 335 & 0.30 & 530 & 0.23 \\
\hline
\end{tabular}

Note: $\lambda_{A}$ and $\lambda_{B}$ are the maxima of absorption bands of the initial $A$ and photoinduced $\mathrm{B}$ forms; $D_{\mathrm{A}}-$ value of the optical density at the maximum of the absorption band for the initial form $\mathrm{A} ; \Delta D_{\mathrm{B}}^{\text {phot }}-$ the value of a photoinduced change of optical density at the maximum of the photoinduced form $\mathrm{B}$ in the photo-equilibrium state.

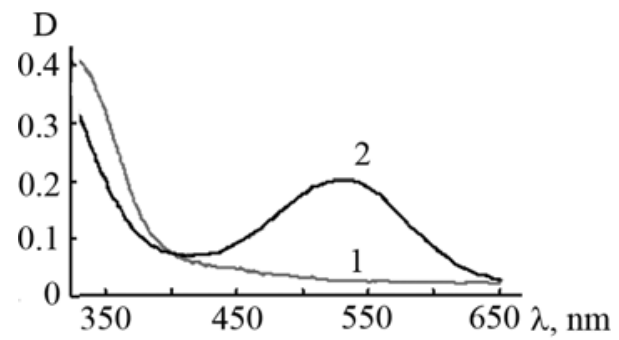

Fig. 5. Absorption spectra of the photochromic film based on the compound II and PTFE before (1) and after (2) UV irradiation.

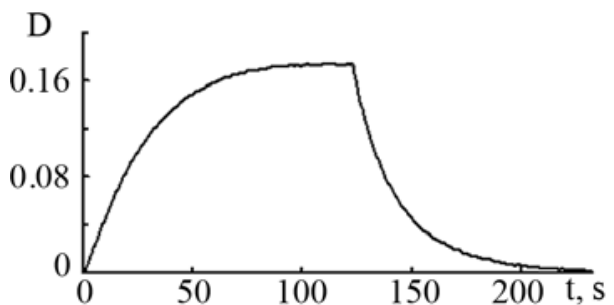

Fig. 6. Kinetic curves for processes of photocoloration under UV irradiation through the filter $\mathrm{У} Ф \mathrm{C}-1$ (1) and photobleaching under visible irradiation through the filter ЖC -16 (2) for the film based on the compound II and PTFE at the maximum of absorption band of the form $\mathrm{B}$.

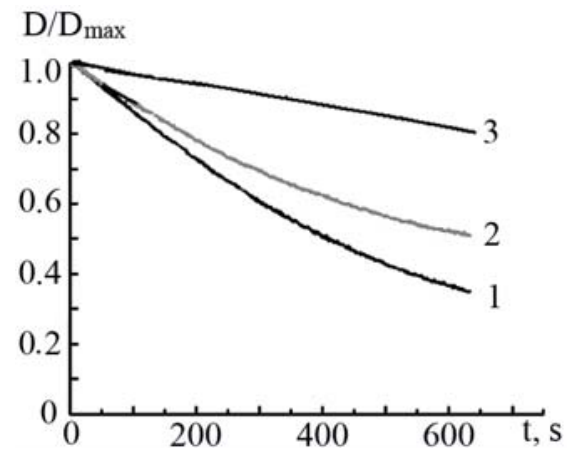

Fig. 7. Normalized kinetic curves of the photodegradation process for polymeric films prepared using photochromic fulgimide II and PTFE $(1,2)$ and PMMA (3) at $D_{\mathrm{A}}=0.14(1)$, 0.29 (2); 0.30 (3). 
Unlike the compound I, the films based on the compound II prepared by the spin-coating are more photostable as compared with the vacuum deposited films (Fig. 7). Their photostability grows with the compound concentration increase similar to that of films based on the compound I.

Our analysis of the obtained results show one important advantage for application of photochromic films prepared by vacuum co-deposition of thermally irreversible diarylethenes or fulgimides and PTFE in the development of optical memory. Unlike films prepared by spin-coating method, these films contain a high concentration of photochromic compounds in thin layers $(30 \ldots 60 \mathrm{~nm})$. This property allows to increase information capacity and to decrease the thickness of multilayer photochromic recording media for $3 \mathrm{D}$ optical memory.

\section{Conclusions}

Thin photochromic films were prepared by co-deposition in vacuum of thermally irreversible diarylethene and fulgimide with polytetrafluoroethylene for the first time. The produced films are characterized by high light sensitivity and thermal stability of both forms. These photochromic layers open perspectives for development of multilayer optical disks with high information capacity for two-photon bitwise working optical memory.

\section{Acknowledgements}

This work was supported by the Presidium of the Russian Academy of Sciences and by the theme No 3-41-07 funded by National Academy of Sciences of Ukraine

References

1. K.P. Gritsenko and A.M. Krasovsky, Thin film deposition of polymers by vacuum degradation // Chem. Rev. 103, p. 3607-3650 (2003).

2. K.P. Gritsenko, V.F. Machulin, A.O. Ait, A.M. Gorelik, O.I. Kobeleva, T.M. Valova, V.A. Barachevsky, Photochromic films prepared by vacuum co-deposition of polymer and spiropyrans // Optical Memory \& Neural Networks 19, p. 254259 (2010).

3. M. Irie, Photochromism: Memories and Switches Introduction // Chem. Rev. 100(5), p. 1683-1695 (2000).

4. Y. Yokoyama, Fulgides for memories and switches // Chem. Rev. 100(5), p. 1717-1739 (2000).

5. V.A. Barachevsky, M.M. Krayushkin, Photochromic organic compounds for optical memory // Russian Chem. Bull. 57(4), p. 867-875 (2008). 